\title{
Configuração de Monteiro Lobato na crítica à Anita Malfatti (1930)
}

Paula Marinelli Martins ${ }^{1}$

Resumo: $\mathrm{O}$ presente trabalho analisa a crítica publicada no jornal $\mathrm{O}$ Estado de São Paulo em 1917, sob a autoria de Monteiro Lobato e título A Propósito da Exposição Malfatti (republicado em 1919, com o título Paranoia ou Mistificação). A partir de discussões sobre o processo de modernização do Brasil da primeira república e formação do Estado nacional, o trabalho debate Monteiro Lobato enquanto representativo da elite intelectual que tem importante papel no processo de modernização - politizado e crítico sobre o "atraso" do Brasil. A proposta consiste em problematizar os choques internos de elites dirigentes (política e intelectualmente) de um modelo hegemônico de modernidade inexistente através de diversas reações ao processo de modernização, que podem ser negativas e contraditórias, como no caso de Lobato, que defendia a modernidade, mas não a via na arte trazida pelos modernistas.

Palavras-chave: Modernização; Monteiro Lobato; Modernismo.

Abstract: This paper analyzes the critical published in the newspaper O Estado de São Paulo in 1917 under the authorship Monteiro Lobato and title The purpose of the Exposure Malfatti (republished in 1919, with the title Paranoia or Mystification). From discussions on the process of modernization of Brazil's first republic and the formation of the national state, the paper discusses Monteiro Lobato as the representative of the

\footnotetext{
${ }^{1}$ Graduanda em História UFPR.
} 
intellectual elite that has important role in the modernization process politicized and critical about the "backwardness" of Brazil. The proposal is to discuss the internal shocks of elites (political and intellectual) of a hegemonic model of modernity nonexistent through various reactions to the modernization process, which may be negative and contradictory, as in the case of Lobato, who championed modernity, but not seen in the art brought by the modernists.

Keywords: Modernization; Monteiro Lobato; modernism.

O presente trabalho visa análise da crítica publicada no jornal O Estado de São Paulo em 1917, sob a autoria de Monteiro Lobato e intitulado A Propósito da Exposição Malfatti (republicado em 1919 no livro Ideias do Jeca Tatu, com o título Paranoia ou Mistificação?). A partir das discussões acerca do processo de modernização do Brasil da primeira fase da república e formação do Estado nacional, o trabalho tem por objetivo analisar através do artigo a figura de Monteiro Lobato, enquanto representativo da elite intelectual que tem importante papel no processo de modernização - politizado e crítico sobre o "atraso" do Brasil pós-império, o autor é conhecido por sua produção na literatura infantil, porém com grande obra no que se refere à política e modernidade cultural.

A fonte em questão, por tratar-se de um artigo relativamente isolado, necessita de amparo bibliográfico para que nos permita analise sobre seu local de produção, principalmente relativo às especificidades do autor, seu lugar social, matrizes intelectuais e políticas. Além disso, 
cabe também destaque ao movimento modernista, na figura de Malfatti, para o qual é destinada a fonte e de como os argumentos utilizados pelo autor se articulam com o movimento que critica.

Bresciani (1993) define no Brasil pós-proclamação da república, projetos distintos para o país partindo as concepções configuradas ao longo do XIX. Um republicano, de inspiração liberal, enfocando a grande propriedade agrícola e a diversificação da aplicação do capital, e outro de cunho civilizador positivista, vinculado à ampliação da instrução, da tecnificação, implementos mecânicos na agricultura e fundação de indústrias ${ }^{2}$.

O Brasil do início do século XX, especialmente na década de 1910, caminha em busca da construção de uma autenticidade do povo brasileiro. Segundo Lucia Lippi (2003), a elite brasileira estava em viés de quebrar o desejo de "ser europeia" e construir dentro do país suas perspectivas futuras. Nesse espírito de reinvenção é que se volta para o povo brasileiro, onde a literatura regionalista ganha destaque ao falar do amor ao Brasil rural, ao Brasil do interior ${ }^{3}$. Monteiro Lobato, figura-se nesse cenário como um dos principais autores do movimento de elite que se ocupa da construção do verdadeiro brasileiro que habita no

2 BRESCIANI, Maria Stella M. O cidadão da República, positivismo versus liberalismo (Brasil, 1870-1930). In: Revista USP, Dossiê Liberalismo, n.17. São Paulo: Editora da USP, mar-mai 1993. P. 124

${ }^{3}$ OLIVEIRA, Lúcia Lippi. Sinais de modernidade na era Vargas: vida literária, cinema e rádio. IN: FERREIRA, Jorge; Lucília de A. N. DELGADO (Orgs.). O Brasil republicano. O tempo do nacional-estatismo: do início da década de 1930 ao apogeu do Estado Novo. Rio de Janeiro: Civilização Brasileira, 2003, p. 327. 
interior, no sertão, representantes do passadismo do Brasil que necessita de crescimento na instrução e na tecnificação para se fortalecer.

Lobato teorizou a respeito do atraso do país no que se refere à baixa produtividade, o trabalho e a falta de educação técnica voltada para as fábricas. Relacionando-as com a fragilidade do país em comparação com a produção de outros países ${ }^{4}$. No cenário intelectual e cultural, o autor ocupa um espaço privilegiado em meio às produções do país.

Monteiro Lobato era herdeiro de uma grande propriedade rural na qual desse cedo se empenhou em tornar produtiva e rentável, através da implementação de novas técnicas agrícolas em um tempo em que a política econômica - sob o ponto de vista dos fazendeiros paulistas não favorecia a lavoura ${ }^{5}$. É nesse cenário que inicia sua intervenção política através dos artigos para $O$ Estado de São Paulo, a princípio voltado à velhas práticas de cultivo e a política em vigor, ressoando a insatisfação de muitos fazendeiros paulistas. É no jornal que inicia seus projetos como escritor e de empreendedor da cultura.

Em suas obras, marcou-se a valorização da cultura popular, da paisagem da natureza brasileira, daquilo que o autor considerava a realidade das regiões rurais, bem como a necessidade de produtividade,

\footnotetext{
${ }^{4}$ CAMPOS, Andre Luiz Vieira de. A república do picapau amarelo: uma leitura de Monteiro Lobato. São Paulo: Martins Fontes, 1986. Pp. 48-49

5 LAJOLO, Marisa. Monteiro Lobato: a modernidade do contra. São Paulo: Brasiliense, 1985. P. 27
} 
ensino técnico e fortalecimento da indústria. A essa abordagem podemos atribuir o caráter nacionalista de suas obras ${ }^{6}$.

O pensamento articulado na figura de Monteiro Lobato, como já citado, reflete elementos de uma elite em formação sob a influência de ideais progressistas em prol do desenvolvimento racional do capitalismo no Brasil da primeira república. A dicotomia entre "racional" e "irracional" se configura politicamente com a ascensão do positivismo no fim do século XIX e dessa forma, a crítica de Lobato ao modernismo vem em concomitância com a necessidade de afirmação de uma elite racional, letrada e tecnicista em oposição ao liberalismo em crise. Alguns autores da arte, como Aracy Amaral (1972), definem isso como um "passadismo letrado" daqueles que militam em prol de uma elite agrária oligárquica e opõe-se aos avanços da modernidade, seja ela cultural ou política ${ }^{7}$.

A exposição de Anita Malfatti inaugurada em dezembro de 1917, pode definir a marca da chegada de novas tendências estéticas ao país. Malfatti nasceu em São Paulo, e estudou arte em Berlim a partir de 1912, onde aprendeu lições do expressionismo alemão. Em sua primeira exposição de retorno ao Brasil, expôs obras significativas de sua carreira, como A estudante Russa, O Homem Amarelo, O Japonês, O

${ }^{6}$ CARDOSO, Renata Gomes de. A crítica de arte no entorno de Anita Malfatti e seu reflexo na história da arte brasileira. Revista de História da Arte e Arqueologia. Campinas, UNICAMP, $\mathrm{n}^{\circ}$ 09, p. 135.

${ }^{7}$ AMARAL. Araci Abreu. Artes Plásticas na semana de 22: subsídios para uma história das artes no Brasil. 2 ed. São Paulo. Perspectiva, 1972. 
Farol e A mulher de Cabelos Verdes ${ }^{8}$. A este evento, Monteiro Lobato, publica em 20 de dezembro de 1917 uma crítica desfavorável à pintora estreante. A crítica configura um abrir fogos de comentários em torno da artista. Em tempos de insurreição, polêmica e lutas sociais, a audácia de Malfatti é vista como exemplo a uns, e de outro lado criticada por ser brasileira, "filha da terra" e contrariar o entendimento dos pontífices brasileiros ${ }^{9}$.

Lúcia Lippi (2003) divide o modernismo no Brasil em dois momentos. Um primeiro momento voltado à aceleração da indústria e dos traços da vida urbana em movimento, principalmente na literatura e nas definições de Mário de Andrade as diretrizes estéticas do movimento ${ }^{10}$. Para a autora, as diversas correntes do modernismo vinculam-se a sua relação com a tradição, definindo diversamente o que importa nas tradições e como elas podem ser atualizadas.

Partindo desse pressuposto, situo a exposição inicial de Malfatti em 1917 como o início da composição estética deste movimento, pouco relacionado às concepções tradicionais e vinculada a artistas das grandes metrópoles mundiais (Anita Malfatti havia estudado em Berlim, Paris e Nova York).

\footnotetext{
${ }^{8}$ Idem p. 244

${ }^{9}$ ALMEIDA, Paulo Mendes de. De Anita ao museu. São Paulo: Perspectiva, 1976. ${ }^{10}$ OLIVEIRA, Lúcia Lippi. Sinais de modernidade na era Vargas: vida literária, cinema e rádio. IN: FERREIRA, Jorge; Lucília de A. N. DELGADO (Orgs.). $O$ Brasil republicano. O tempo do nacional-estatismo: do início da década de 1930 ao apogeu do Estado Novo. Rio de Janeiro: Civilização Brasileira, 2003, p. 328
} 
Algumas críticas contra os modernistas, encabeçadas por Lobato, partem de um ultranacionalismo tradicional alegando o internacionalismo dos modernistas ${ }^{11}$.

Entretanto, seduzida pelas terias do que ela chama arte moderna, penetrou nos domínios dum impressionismo discutibilíssimo, e põe todo o seu talento a serviço duma nova espécie de caricatura. Sejam sinceros: futurismo, cubismo, impressionismo e tutti quanti não passam de ouros tantos ramos da arte caricatural. ${ }^{12}$

Neste trecho, o autor cita explicitamente as convencionadas "vanguardas", definindo-as como arte caricatural, caricatura de cor, caricatura de forma que não visa ressaltar uma ideia, mas sim, desnortear e atrapalhar o espectador ${ }^{13}$. O interessante dessa argumentação é a relação direta entre a arte moderna e uma sedução europeia e norte americana. Ainda que, no decorrer da crítica recorra a exemplos de artistas suecos, ingleses e franceses da época, sua tradição de escrita regional, e defesa de intelectuais e bacharéis que se voltem para as questões sociais brasileiras, nos permitem identificar nessa depreciação da influência modernista internacional como parte de sua crença no fortalecimento da nacionalidade.

\footnotetext{
${ }^{11}$ AMARAL. Araci Abreu. Artes Plásticas na semana de 22: subsídios para uma história das artes no Brasil. 2 ed. São Paulo, perspectiva, 1972.

${ }^{12}$ LOBATO, Monteiro. Paranóia ou Mistificação? In: Ideias de Jeca Tatu. São Paulo: Brasiliense, 1959. P. 61

${ }^{13}$ Idem. p. 61.
} 
Durante o artigo, Lobato demonstra certa erudição a respeito das vanguardas artísticas, e identificando o movimento modernista, neste momento na figura de Anita Malfatti, como um grande importador de tendências, que, ao olhar do escritor, não apresentam nada a ser valorizado, muito menos uma inovação. Ao dividir a arte citando duas espécies de artistas: "os que veem normalmente as coisas e em consequência disso fazem arte pura" e os que "veem anormalmente a natureza, e interpretam-na à luz de teorias efêmeras, sob a sugestão estrábica de escolas rebeldes", colocam Malfatti e os demais vanguardistas do período no segundo grupo, daqueles que são "estrelas cadentes" que logo irão para as "trevas do esquecimento"14. Isto porque, o caráter inovador ou vanguardista da concepção estética de Malfatti é questionado e negado pelo autor e é o que define o título dado ao texto em sua segunda edição: Paranóia ou Mistificação?

Embora eles se dêem como novos precursores duma arte a ir, nada é mais velho de que a arte anormal ou teratológica: nasceu com a paranóia e com a mistificação. De há muitos já que a estudam os psiquiatras em seus tratados, documentando-se nos inúmeros desenhos que ornam as paredes internas dos manicômios. A única diferença reside em que nos manicômios esta arte é sincera, produto ilógico de cérebros transtornados pelas mais estranhas psicoses; e fora deles, nas exposições públicas, zabumbadas pela imprensa e absorvidas por

\footnotetext{
${ }^{14}$ Ibidem. p. 59.
} 
americanos malucos, não há sinceridade nenhuma, nem nenhuma lógica, sendo mistificação pura. ${ }^{15}$

O trecho supracitado sintetiza o pensamento de Monteiro Lobato a respeito da obra de Malfatti, e nos fornece elementos para articular suas motivações ao escrever este artigo, e influencias de sua militância política.

Ao defender o caráter anormal e monstruoso da exposição, em prol de uma sinceridade e da importância da lógica, o autor demonstra seus problemas com as novas manifestações artísticas: elas não têm um padrão, não são passíveis de explicação, só podendo ser atribuídas a um subconsciente de alguém transtornado por algum tipo de psicose. Em um espaço de produção voltado para o valor da técnica, da razão como sinônimo de progresso, depredar a imagem da pintora como alguém irracional é um dos elementos mais significativos da obra, tanto que, na reedição da publicação em 1919, o título passa a ser Paranóia ou Mistificação? Com o objetivo de enfatizar o caráter irracional, psicótico e paranoico não só daqueles que produzem aquela arte, mas como do público que o aprecia. $\mathrm{O}$ autor dedica boa parte da crítica a depredar a reação do receptor ao deixar a exposição:

A fisionomia de que sai de uma destas exposições é das mais sugestivas. Nenhuma impressão de prazer, ou de beleza denuncia as caras; em todas, porém, se lê o desapontamento de quem está incerto, duvidoso

${ }^{15}$ Ibidem. P. 60 
de si próprio e dos outros, incapaz de racionar, e muito desconfiado de que o mistificam habilmente. ${ }^{16}$

Ser incapaz de raciocinar. É essa a impressão causada pelas obras de Anita Malfatti ao seu público segundo Monteiro Lobato. Como já descrito, a razão, expressa na instrução, na ciência e na técnica são, para alguns integrantes da elite intelectual, elementos fundamentais ao progresso. Essa construção positivista elimina a possibilidade da indeterminação, considera anômalo aquilo que não se alia a razão, precisando ser reeducado ou até mesmo excluído.

O movimento identificado como modernismo no Brasil, surge, portanto como uma vanguarda cultural que rompe com o academicismo em busca da descentralização da razão. É a crise do liberalismo, com a perda da importância da "certeza" afetando setores importantes da sociedade, sobretudo com o advento da cultura de massa que convive com a diversidade estética e de escrita.

Outro aspecto a ser destacado na crítica é a ausência de uma técnica perceptível. Em toda sua produção cultural, Lobato elabora uma técnica de mercado para suas obras, desde o título, obra, preço e propaganda. Vinculado aos ideais elitistas de progresso capitalista, de necessidade de impulsionar a indústria voltada a massa, o autor foi um dos pioneiros da industrialização da cultura enquanto mercadoria comercialmente lucrativa, sobretudo após tornar-se proprietário e editor

\footnotetext{
${ }^{16}$ LOBATO, Monteiro. Paranóia ou Mistificação? In: Ideias de Jeca Tatu. São Paulo: Brasiliense, 1959. P. 61
} 
da Revista Brasil ${ }^{17}$. Nesse momento, o autor confronta as concepções estéticas e metodologia de produção de Malfatti e suas influências internacionais, com outros artistas mais voltados a técnicas tradicionais sem deixar de ser esteticamente "modernos" no ponto de vista de Monteiro Lobato:

Como se não fosse moderna, moderníssima, toda a legião atual de incomparáveis artistas do pincel, da pena, da água-forte, da dry point que fazem da nossa época uma das mais fecundas em obras-prima de quantas deixaram marcos de luz na história da humanidade. ${ }^{18}$

Sobre a técnica, ou falta dela, de Bolynson, professor de Malfatti nos Estados Unidos:

Tenhamos coragem de não ser pedante: aqueles gatafunhos não são uma figura em movimento; foram, isto sim, um pedaço de carvão em movimento. O Sr. Bolynson tomou-o entre os dedos das mãos ou dos pés, fechou os olhos, e fê-lo passar na tela às pontas, da direita para a esquerda, de alto a baixo. E se não o fez assim, se perdeu uma hora da sua vida puxando riscos de um lado para o outro, revelou-se tolo e perdeu tempo, visto como o resultado foi absolutamente o mesmo. ${ }^{19}$

\footnotetext{
${ }^{17}$ LAJOLO, Marisa. Monteiro Lobato: a modernidade do contra. São Paulo: Brasiliense, 1985. P. 30.

${ }^{18}$ LOBATO, Monteiro. Paranóia ou Mistificação? In: Ideias de Jeca Tatu. São Paulo: Brasiliense, 1959. P.62

${ }^{19}$ Idem. p. 63
} 
A crítica a ausência de técnica por parte dos modernistas, se relaciona novamente com a concepção racionalista de progresso e crise da centralidade da razão trazida pelo movimento. Não possuir técnica colocava em choque a argumentação das elites, e de Lobato, sobre o despreparo da população brasileira para o Estado de progresso "evoluído", necessitando as elites ocuparem o lugar de dirigentes. Esteticamente, essa "confusão" significava uma quebra dessa concepção. Quem vê a exposição e constata, como Lobato, ausência de técnica, conclui não ser necessária a instrução para este tipo de atividade.

O horror de Lobato a esta ideia é evidente ao criticar Bolyson e descrever de maneira imaginativa sua metodologia de forma a depreciala e torna-la sinônimo de algo ridículo ou patético, afinal, a figura de um homem segurando um carvão com os pés, de olhos fechados, causa ao leitor certo desconforto, se não incredulidade em tal indivíduo. Dessa forma se sustenta a construção de uma imagem negativa dos artistas envolvidos na composição da exposição que serve de elemento de sustentação para a desvalorização do movimento que na republicação do artigo em 1919, já havia se fortalecido nos escritos de Oswald e Mario de Andrade.

Estes e outros críticos envolvidos no entorno de Anita Malfatti, também são alvo da crítica de Lobato. No encerramento do texto, tece alguns elogiosos comentários ao talento da artista, e justifica-se por seu pioneirismo no tratamento a ela com suas considerações desagradáveis. 
Atribuindo aos elogios por ela recebidos uma lisonja perigosa e falsa, de pessoas podem transviar seu caminho daquilo que ele considera melhor ao seu talento:

Os homens têm o vezo de não tomar a sério as mulheres. Essa é a razão de lhes derem sempre amabilidades quando elas pedem opinião. Tal cavalheirismo é falso, e sobre falso, nocivo. Quantos talentos de primeira água se não transviaram arrastados por maus caminhos pelo elogio incondicional e mentiroso $?^{20}$.

Dessa forma, Lobato coloca a sua opinião sobre a exposição e sobre o modernismo acima das críticas elogiosas por considerar seus comentários sinceros para o bem da arte, ao contrário dos cavalheiros que, por não darem o devido valor ao talento da artista, a elogiam sem medir consequências. Essa incredulidade na possibilidade de que alguém possa realmente ver beleza e arte nas obras de Malfatti podemos atribuir duas motivações.

Uma primeira, já acima relacionada, a descrença de que alguém com capacidades racionais desenvolvidas estaria seguro ou consciente de si o suficiente para apreciar essas obras. Lembremos que para Lobato, trata-se do resultado de uma mente paranoica digna de acompanhamento psiquiátrico. Sendo assim, apreciar essas obras também só poderia ser resultado de mentes insanas ou educadas demais

${ }^{20}$ Ibidem. P. 64 
para envolver-se seriamente com aquela produção, e o autor prefere apostar na segunda hipótese ao invés de atacar moralmente seus colegas críticos de arte.

Em segundo lugar, o ataque aos companheiros de Malfatti pode refletir a relação de Monteiro Lobato com estes senhores mais diretamente no campo da literatura. Quando republicado, Oswald de Andrade já estava em vias de publicar os primeiros ensaios e manifestos do movimento modernista. $\mathrm{O}$ embate literário entre estes autores nos rende outra análise mais aprofundada, cabe aqui apenas destacar que o ataque de Lobato aos críticos favoráveis a exposição Malfatti é reflexo do embate pessoal do autor com estes personagens.

A partir destas analises, podemos concluir alguns elementos a respeito da figura de Monteiro Lobato e seu papel durante a formação do Estado Nacional enquanto representante de uma elite intelectual agrária. As concepções de fato sobre o desenvolvimento do país econômico e comercialmente, refletem em sua produção cultural bem como na sua relação com os demais meios de intervenção artística.

A crítica analisada neste artigo se refere exclusivamente às artes plásticas, e de como este personagem se posiciona neste meio: um homem letrado, dotado de razão, sincero, e por isso superiormente capaz de tecer comentários coerentes com os interesses do público da exposição. Este posicionamento, no entanto, também se estende aos demais setores em que o autor se insere, seja na literatura, no cinema e no cenário político do país como um todo. O ideal positivista, 
progressista e tecnicista em oposição a qualquer coisa que remonte a desordem, falta de técnica ou de instrução, é um traço marcante das elites em formação na política brasileira republicana. Tais valores, somados a posição privilegiada de Monteiro Lobato, proprietário rural e posteriormente editor de uma revista de grande circulação, nos fornecem um personagem fundamental nos conflitos que irão marcar a década de 1920 no Brasil, sobretudo com a crise do liberalismo e da centralidade da razão, por ser Lobato e a imprensa de modo geral grande veículo destes conflitos.

\section{Referências}

Fonte: LOBATO, Monteiro. Paranóia ou Mistificação? In: Ideias de Jeca Tatu. São Paulo: Brasiliense, 1959.

ALAMBERT, Francisco. A semana de 22: a aventura modernista no Brasil: livro do professor. São Paulo: Scipione, 1992.

ALMEIDA, Paulo Mendes de. De Anita ao museu. São Paulo: Perspectiva, 1976.

AMARAL. Araci Abreu. Artes Plásticas na semana de 22: subsídios para uma história das artes no Brasil. 2 ed. São Paulo, perspectiva, 1972.

BRESCIANI, Maria Stella M. "O cidadão da República, positivismo versus liberalismo (Brasil, 1870-1930)", in: Revista USP, Dossiê Liberalismo, n.17. São Paulo: Editora da USP, mar-mai 1993. 
CAMPOS, Andre Luiz Vieira de. A republica do picapau amarelo : uma leitura de Monteiro Lobato. São Paulo: Martins Fontes, 1986.

CARDOSO, Renata Gomes de. A crítica de arte no entorno de Anita Malfatti e seu reflexo na história da arte brasileira. Revista de História da Arte e Arqueologia. Campinas, UNICAMP, nº 09, pp. 127147, 2008.

LAJOLO, Marisa. Monteiro Lobato: a modernidade do contra. São Paulo: Brasiliense, 1985.

LOBATO, Monteiro et al. Monteiro Lobato. São Paulo: Perspectiva, 1985.

OLIVEIRA, Lúcia Lippi. Sinais de modernidade na era Vargas: vida literária, cinema e rádio. IN: FERREIRA, Jorge ; Lucília de A. N. DELGADO (Orgs.). O Brasil republicano. O tempo do nacionalestatismo: do início da década de 1930 ao apogeu do Estado Novo. Rio de Janeiro: Civilização Brasileira, 2003, pp.323-349.

VALE, Lucia de Fátima do. A propósito da Exposição Malfatti, Edição Revisitada. Revista Urutágua. Maringá, Universidade Estadual de Maringá, nº 07, 2005. 